\title{
Identity, Role, and Oppression: Experiences of LGBTQ Resource Center Graduate Assistants
}

\section{Chase Catalano \& Daniel Tillapaugh}

To cite this article: D. Chase Catalano \& Daniel Tillapaugh (2020): Identity, Role, and Oppression: Experiences of LGBTQ Resource Center Graduate Assistants, Journal of Student Affairs Research and Practice, DOI: 10.1080/19496591.2019.1699104

To link to this article: https://doi.org/10.1080/19496591.2019.1699104

\section{Published online: 06 Jan 2020.}

Submit your article to this journal $\square$

Q View related articles $\sqsubset$

View Crossmark data $[\pi$ 


\title{
Identity, Role, and Oppression: Experiences of LGBTQ Resource Center Graduate Assistants
}

\author{
D. Chase Catalano, Virginia Polytechnic Institute and State University \\ Daniel Tillapaugh, California Lutheran University
}

\begin{abstract}
Utilizing oppression as a conceptual framework, this article explores themes that emerged from qualitative research using epistemological bricolage on data from five graduate assistants who served as the sole institutional contact for LGBTQ+ student services. Of particular attention was the influence of these students' multiple social identities on their 10 direct work experiences, the graduate assistant role itself, perceptions of institutional visibility of LGBTQ work, and implications of oppression on practice.
\end{abstract}

There are over 320 higher education institutions with a lesbian, gay, bisexual, transgender, and queer resource center (LGBTQRC; Consortium of Higher Education LGBT Resource Professionals [the Consortium], 2017). Comparatively, the number of LGBTQRCs to the total number of colleges and universities in the United States is small. Yet, the steadily increasing number of LGBTQRCs should garner attention to the experiences of those who work within them. As Renn (2010) noted, "studies of the experiences and identities of LGBT faculty, staff, and executive leaders have been nearly absent" (p. 136). We chose to focus our attention on understanding the experiences of graduate assistants (GAs) who were the sole staff member at their public university's LGBTQRC. In our first publication from this research, we focused on the structural challenges that influenced the experiences of GAs (Tillapaugh \& Catalano, 2019). Our research found these GAs felt set up for failure through the location of their LGBTQRC, received inconsistent supervisory support, lacked formal job training, and received limited budgetary and time resources (Tillapaugh \& Catalano, 2019). In thinking about structural challenges for these GAs, we returned to the data to examine how heterosexism and trans* oppression (Catalano \& Griffin, 2016) may mediate these GAs' work experiences.

The purpose of this qualitative study was to explore the experience of GAs whose assistantship is within lesbian, gay, bisexual, transgender, and queer (LGBTQ+) student services ${ }^{1}$ and serves as the

Correspondence concerning this article should be addressed to D. Chase Catalano, School of Education, Suite 2000, 1750 Kraft Drive, Blacksburg, VA 24061. E-mail: ccatalano@vt.edu

${ }^{1}$ Due to variations in language, we utilize LGBTQ+ student services to refer broadly to a functional area of student affairs work, and LGBTQResource Centers (LGBTQRC) specifically regarding departments where that work happens. Faced with the impossibility of language that adequately attends to the myriad number of marginalized sexualities and genders in higher education, and with an awareness that names matter (Marine \& Nicolazzo, 2014), we chose an acronym that inclusively addresses these communities and previous literature, accepting there will be criticism of any acronym. 
only professional staff member in that office. The lack of research on student affairs graduate assistantships compounds the limited research on LGBTQRC professionals, which results in a significant absence in the higher education literature. Examining the experiences of these GAs allows for a critical view of heterosexism and trans* oppression in the context of higher education.

Our two research questions for this study were:

1. What are the critical influences that affect GAs who serve as the single point of contact for LGBTQ+ student services at their public university?

2. In what ways do these GAs' social and personal identities affect their overall experiences of their roles on campus?

\section{Literature Review}

LGBTQRCs first appeared in student affairs in 1971 (Fine, 2012) initially to serve sexual minoritized (later trans* and gender minoritized) students, to combat hostile campus environments and lack of institutional policies and practices (Evans \& Rankin, 1998; Marine, 2011). Kortegast and van der Toorn (2018) pointed out there is a gap in the literature about LGBTQ+ professionals in general, which echoes claims made by other scholars about LGBTQRC staff (Marine, 2011; Pryor, Garvey, \& Johnson, 2017; Sanlo, 2000). LGBTQRCs, like other identitybased/cultural centers, address issues of social justice and inclusion in higher education (Cuyjet, Howard-Hamilton, Cooper, \& Linder, 2016; Patton, 2011; Stewart, 2011). Those who work in LGBTQRCs program and educate about LGBTQ+ experiences and histories, as well as critically engage audiences on a plethora of identity nuances within these marginalized genders and sexualities (Jenkins \& Walton, 2008). The scant literature on GAs responsible for this work was an initial motivation for our research.

The increased presence of LGBTQRCs on campuses across the United States offers positive impacts on campus climate, although they are not the panacea needed to eradicate heteronormativity, cisnormativity, and other forms of erasure and marginalization for LGBTQ+ students (Pitcher, Camacho, Renn, \& Woodford, 2016). The presence of an LGBTQRC provides an institutional declaration to combat heterosexism and trans* oppression. "An office dedicated to supporting LGBTQ + students could provide resources for education, individual and group development, and fostering a sense of belonging, as well as provide a strong symbol for a campus commitment to LGBTQ+ student success" (Pitcher et al., 2016, p. 12). Yet, much of the literature on LGBTQRC staffing patterns focuses on the formation of these centers (e.g., Marine, McLoughlin, \& McCarthy, 2015) and the contemporary benefits and purpose of LGBTQRCs based on an organizational perspective (Pitcher et al., 2016). Our research sought to attend to staffing dynamics as part of the function of these centers, specifically the relative merits of GAs who lead these centers.

GA positions are typically part-time positions, approximately 20 hours per week, with contracts that last an academic year (Sanlo, 1998). Most GAs in student affairs positions are in master's degree programs that last one or two years, which diminishes continuity and results in high burnout rates (Sanlo, Rankin, \& Schoenberg, 2002). These graduate assistantships may financially benefit their institution, but the high turnover rate translates to loss of institutional memory to sustain programs and services (Sanlo et al., 2002). The GAs in our study had sole responsibilities for these LGBTQRCs, as opposed to LGBTQRCs with full-time staff in this same role. As enrolled students in their specific institutions' higher education and student affairs (HESA) program, participants sought to combine academic content with socialization to higher education through their GA 
positions (Kuk \& Cuyjet, 2009). In their GA positions, they led initiatives to provide LGBTQ+ advocacy on campus, policy development, advising student organizations, student development, and education and training (Marine, 2011; Pitcher et al., 2016).

\section{Conceptual Framework}

Historically, within the United States as well as throughout the world, LGBTQ+ individuals experience oppression due to their sexual and gender identities. The result of these historical roots are heterosexism and trans* oppression (Catalano \& Griffin, 2016). Structural and institutional manifestations of heterosexism and trans* oppression such as policies, procedures, and legislation create discord and barriers for individuals who identify as sexual and/or gender minorities. The framework of oppression allows for analyzing and evaluating these structures and practices via the five different categories: exploitation, marginalization, powerlessness, cultural imperialism, and violence (Young, 1990). Previous scholars use of Young's (1990) five faces of oppression as a conceptual framework include studies on women's engagement in computer science majors in college (Michell, Szorenyi, Falkner, \& Szabo, 2017) and youth oppression (DeJong \& Love, 2015). Therefore, Young's (1990) work serves as a useful tool of analysis for understanding the condition of LGBTQ+ people and for this particular study, LGBTQ+ student services in higher education.

Young (1990) offered that each criterion within the five faces "can be applied through the assessment of observable behavior, status, relationships, distributions, texts and other cultural artifacts" (p. 64). The use of the criteria resists reductionism in the analysis of multiple forms of oppression (i.e., racism, classism, heterosexism). "Justice should refer not only to distribution, but also to the institutional conditions necessary for the development and exercise of individual capacities and collective communication and cooperation" (Young, 1990, p. 39). Our efforts in this research are to understand how to analyze the presence and absence of justice for the students our participants serve, as well as the ways GAs experience agency and resistance in their work life and environments. We utilized Young's (1990) framework to direct our analysis of the experiences of our participants on individual, institutional, and systemic levels.

\section{Methods}

Our study utilized qualitative methods, specifically case study design (Yin, 2003) and crosscase synthesis to analyze our data; cross-case synthesis allowed us to see each participant as a unique case or study, and then "aggregat[e] findings across a series of individual studies" (Yin, 2003, p. 134). We chose a cross-case study design because of our interest in understanding the complexity of these GAs' work experiences, each at a different public four-year university.

We returned to our previously collected data using a constructivist framework and applied a critical theory lens to convey its complexity, engaging in epistemological bricolage (Kincheloe, 2001). While scholars are often trained to examine data from one particular theoretical paradigm, epistemological bricolage troubles this stance, recognizing "the limitations of a single method, the discursive strictures of one disciplinary approach, [and] what is missed by traditional practices of validation" (Kincheloe, 2001, p. 681). Pulling from multiple theoretical perspectives, epistemological bricolage has been used in a number of studies focusing on identity development in higher education, including Abes (2009) and Tillapaugh and Nicolazzo (2015). We wanted to problematize how systemic issues of power and oppression played into the identity aspect of these GAs' work experiences. This aligns with Abes' (2016) work, where she wrote, 'The underlying assumption of critical perspectives is that power and systems of oppression shape 
Table 1

Participant Demographics

\begin{tabular}{|c|c|c|c|}
\hline Participant & Institution & Identities & Time in position \\
\hline Aaron & $\begin{array}{l}\text { Rocky Mountain } \\
\text { University }\end{array}$ & Black, gay, cisgender, man & 1 semester-transferred to different site \\
\hline Chad & $\begin{array}{l}\text { Midwestern } \\
\text { University }\end{array}$ & $\begin{array}{l}\text { White, homoflexible, cisgender, } \\
\text { man }\end{array}$ & $\begin{array}{l}\text { In } 2 \text { nd full academic year in site at time of } \\
\text { interviews }\end{array}$ \\
\hline Nick & $\begin{array}{l}\text { University of the } \\
\text { Midwest }\end{array}$ & White, gay, cisgender man & In 1 st year of position at time of interview \\
\hline Paula & $\begin{array}{l}\text { Great Plains } \\
\text { University }\end{array}$ & $\begin{array}{l}\text { White, heterosexual, cisgender, } \\
\text { woman }\end{array}$ & $\begin{array}{l}\text { In 2nd full academic year at time of } \\
\text { interviews }\end{array}$ \\
\hline Seth & $\begin{array}{l}\text { Great Lakes } \\
\text { University }\end{array}$ & White, gay, cisgender, man & In 1st year of position at time of interview \\
\hline
\end{tabular}

reality” (p. 12). By employing Young's (1990) five faces of oppression as a lens, we engaged with "the political discourse in which oppression is a central category" (p. 39) and involves a "general mode of analyzing and evaluating social structures and practices" (p. 39).

We utilized public data listed by the Consortium (2017) to determine campuses with graduate students as the primary person responsible for LGBT student services. Calls for participants went through the Consortium listserv and a HESA program faculty listserv. Then, we e-mailed individuals who fit the study's criteria to invite them to participate, using purposeful sampling (Patton, 2002), and secured five participants who were full-time students enrolled in their university's HESA program (Table 1). In the following, we provide a brief introduction to the participants (all individual and institution names are pseudonyms).

We used a semi-structured interview protocol for the three phone interviews conducted over one academic year. To ensure continuity, we interviewed the same participants over the year. In Fall 2014, we conducted the first interviews about their training and preparation for their position and their initial experiences on the job. The second interviews, held in Winter 2015, explored participants' experiences within the position, particularly the organizational structure of their university and their thoughts on their formal and informal authority within their role. The final interviews, conducted in Spring 2015, served as a wrap up about their experiences, any challenges they faced, and their recommendations on improving their work experience. Interviews lasted between 45-minutes to an hour in length and transcribed verbatim.

Participants reviewed their transcripts for accuracy as a form of member checking and data triangulation. After participants verified the accuracy of their transcripts, we swapped transcripts for analysis whereby we reviewed and then coded the transcripts of those participants we had not interviewed. We followed Yin's (2003) principles for case study analysis; this included (a) examining all relevant evidence of the cases, (b) interrogating rival interpretations, (c) highlighting significant aspects of the case study, and (d) using our content expertise to understand the topic. After analyzing the individual transcripts, we collaboratively identified themes and patterns that cut across each of the cases, ensuring that we kept focus on the research questions that guided the study. 


\section{Researchers' Positionality}

As a part of our analysis, we engaged in a reflexive process to consider our positionality in relation to our study. Prior to becoming faculty, we worked in LGBTQ+ student services in higher education. Chase served as the director of his campus LGBTQRC for several years; Dan maintained a collateral assignment outside of his full-time job for three years as his campus's LGBTQ+ student services liaison. We believe wholeheartedly in the mission of LGBTQ+ services yet remain skeptical about how higher education institutions support cultural center work on most college and university campuses, particularly LGBTQRCs. Our concern stemmed from an observable increase in LGBTQRCs on college and university campuses; many seemingly staffed by one single GA. We both identify as members of the LGBTQ+ community; Chase identifies as queer and trans while Dan is queer and cisgender. We both identify as White. Our concerns center on how administrators at colleges and universities value cultural center work but do not provide requisite levels of support and resources for such work. We have concerns about senior level administrators' decisions, seemingly informed by neoliberal philosophies, to create LGBTQRCs staffed solely by graduate students on their campus as a signal of inclusion without fully understanding the consequences of such decisions.

\section{Findings}

We focus our findings on the implications and influences of participants' identities on their experiences as the sole LGBTQRC staff member. Participants' articulations of the influence of their identities (privileged and minoritized) shape their relationships to self-awareness and efficacy perceptions, working with others, and institutional external imagery. Our findings discuss themes of identity influence, GA role, and institutional focus on external perceptions.

\section{Identity Influence}

Participants were cognizant of how their social identities surfaced in their work. Specifically, they discussed the influences of their minoritized and dominant identities on their professional endeavors. Thus, two sub-themes emerged around identity influence: (a) the centering of LGBTQ + awareness and (b) intersections of race and LGBTQ+ work.

Centering LGBTQ+ Awareness. Given the number of identities that fall under the LGBTQ+ umbrella, it would be difficult for any one person to identify within all communities. Serving as the sole LGBTQ+ student services staff member provided participants with various opportunities to understand how their identities influenced their work. Participants noted the ways their dominant identities both helped and hindered their work. Paula was acutely aware of how her identity as a heterosexual ally might impact her ability to be successful. "I didn't even want to do this position mostly because like I said, as an ally I have so many privileges it just felt wrong to be in this position" (Paula). She continuously referenced her ally identity as a source of uncertainty and struggle because of her heterosexual identity. Conversely, Seth described feeling a responsibility to be a visible representation of the LGBTQRC, responsible to be " ... the institutional rock of the community" and the "public face" of the campus LGBTQ+ community.

All the participants identified as cisgender, and many spoke about the challenges of understanding how to best support transgender and gender non-conforming students. Chad, Nick, and Paula engaged in specific work around creating gender inclusive restrooms and general trans inclusion. Yet, strong feelings of helplessness surfaced about how they would "never be enough," a reflection of lacking both queer and trans content knowledge given their own identities. Paula stated: 
I tell students all the time that I am not an expert, and I learn things all the time. Some of the students might know more than I do, but really what I do-I'm a safe person for students to talk to.

This was a statement she made several times throughout our interviews, reiterating her feeling underprepared to fully understand the experience of the students she was attempting to support.

Nick mentioned that he utilized his experience attending the National Gay and Lesbian Task Force (NGLTF) Creating Change Conference as an opportunity to learn, "specifically regarding trans students and how to help them better." He utilized his experience to grow in an area he thought he needed more education. Nick's new content knowledge increased his awareness of institutional and systemic dynamics of oppression, motivating him to impact campus climate through programming. He wanted to utilize his cisgender privilege to advocate for changes on campus for trans students.

Our participants attempted to advocate for students with experiences that were unfamiliar or unknown to them, which was a challenge. Identifying within LGBTQ+ communities required a different kind of allyship, one of across and within identity groups. Seth named his willingness to learn more and his limitations when it came to Queer People of Color (QPOC) and Queer People of Color with Disabilities (QDPOC):

So ... I think I've definitely had to ... maybe take the extra step that, to show that I am an ally to those communities. I think, it hasn't happened as much this year, but definitely last year I had some key LGBTQ Students of Color, QPOC, QDPOC, students definitely connect with me ... there are some conversations I don't need to be a part of, but when they need me, I am, I'm there. And they know that. (Seth)

He found ways to communicate his awareness of how QPOC and QDPOC students experience the campus differently than him and attempted to demonstrate his allyship to be there for them. In their roles, participants recognized how salience with various social identities influenced students' assertions of needs of them and the LGBTQRC. Concurrently, participants struggled under the false assumption that a straight ally or someone who identifies as a sexual minority meant that they had adequate knowledge to serve all LGBTQ+ students.

The Intersections of Race and LGBTQ+ Work. The intersections of race and LGBTQ+ identities surfaced for participants, particularly around being conscious of the racial demographics of students who entered their centers and who were a regular part of those spaces. Many participants noted few Students of Color regularly used their spaces, and their centers seemed very White-identified. For Chad, Nick, Paula, and Seth, their understanding of their Whiteness varied and played a role in how they thought about the intersections of race, sexuality, and gender in their work. Seth took part in consciousness-raising groups on Whiteness as an undergraduate and felt more comfortable with intersections of race, gender, and sexuality; for other White participants, they noticed racial dynamics within the LGBTQRC but were uncertain of how to change it. For instance, Chad believed there was work he wanted to do but acknowledged his reluctance to engage in some work on campus as a White able-bodied man. “[I] didn't get deep into intersectionalities of race and ability.... Just because I didn't feel qualified or comfortable speaking of those" (Chad). He was aware QPOC did not feel comfortable with the LGBTQ+ student organization, and as their graduate advisor, he had to work through the tensions. Chad's dominant identities and subsequent privilege granted by those identities resulted in not engaging in important conversations toward true allyship. Chad's comments here represent what most of our White participants' experiences were around race: silence. For most of the White participants with the exception of Seth, they continued their work 
that primarily focused on White LGBTQ+ students on their campus who predominantly accessed their LGBTQRCs.

Aaron, as a Black queer man, had a different perception about his role. He felt overly targeted about what it meant to be Black and leading LGBTQ+ efforts on campus, experiencing a high degree of racial salience as well as many micro- and macroaggressions. Aaron perceived that administrators hoped that his appointment would lead to more QPOC being involved in the center's work. This tokenization was challenging and deeply internalized. He stated:

I'm the only Person of Color in my professional staff office.... There have been a few sort of comments and situations that has just made me feel very uncomfortable. And so that makes it harder for me to do the work that I'm supposed to do especially given that I'm in an office that is seen a lot of times as a "diversity office" or an advocacy office. But it's in a space where none of that work is being done.... We do different work that requires different energy and the things that I need to dothe work I'm doing - are always negatively impacted by the way that other people show up in the space.

This psychic toll created uncomfortable conditions for the work which became extremely dangerous without the necessary and adequate supports in place from his supervisor.

Aaron discussed how his own positionality led to expectations of visible diversity: "I will say that there were certain expectations around my Blackness and my 'awareness' or whatever the case may be, to diversify that space a little bit." His predecessors were White or multi-ethnic (visibly White) cisgender individuals and "the ways that they were able to show up in this space and the things that they have been able to do are a lot different than what I'm experiencing and then how I'm perceived" (Aaron). He described racial representation and sexual minority pressures:

I also think that the fact that I am an identifying person [who is Black and queer] doing work for [racially and sexually] identifying people makes it harder for me to take things less personally and remember my own personal mental and emotional health in these conversations, especially given that I was a student or am a student at the university.

Aaron felt pressure to navigate multiple areas of taxation (personal health and institutional representation) in his GA position. Given that he ultimately transferred out of his position during his first year, the challenges Aaron encountered were not ideal and affected his ability to be successful within his role.

\section{Graduate Assistant Role}

In a previous publication (Tillapaugh \& Catalano, 2019), we described the structural challenges within the participants' GA role; these included: (a) where the students and their LGBTQRC were located structurally within their institution (i.e., the division of student affairs, the division of equity and inclusion), (b) direct supervisors' inconsistent knowledge of LGBTQ+ issues and supervision, (c) lack of professional development and training, and (d) limited resources of money and time. These were all structural challenges that were external to the GAs themselves; in other words, these were all aspects of their job over which they did not have much control. Yet, there were also challenges that affected the students' identity of their professional role as the GA in charge of their university's LGBTQRC; these often resulted broadly in feelings of exploitation. 
In their professional role, their experiences as graduate students surfaced descriptions of feeling inadequate, specifically to accomplish an expectation of completing 40-hours of work within a 20-hour-a-week position. When participants were in classes, did not have office hours, and were on break during summer months, their LGBTQRCs generally closed. Participants felt like it was a failing on their part that their LGBTQRCs had limited hours. They were aware that the expectation of LGBTQRC hours (self-imposed or expected by students and/or supervisors) was unsustainable. As Aaron put it, "I don't feel like I do enough and I also feel like I do way too much. I feel like in having to do so many different things it's like serving roles. It sort of scatters my attention and effort that I can put into things."

The demands of being a full-time graduate student were a limitation to the efficacy in their work. "And it really comes down to being a graduate student and not having the time to make all of the networking needed to make a big change like that" (Paula). The ability to attend meetings, collaborate with colleagues across the institution, and lead efforts for long-term change are limitations of a GA doing the job of a full-time professional in an office of one. Chad mentioned that he was not surprised by the difficulty in the GA position. "[W]ell, it's kind of just the nature of the beast that as a GA you're going to be overworked and underpaid" (Chad). Seth endeavored to keep to around 20 hours per week because "frankly you don't pay me enough to try and do anything more than 20 hours. (laugh)." Even the participants who tried to keep close to the 20 hours per week reported often exceeding their required hours, which negatively affected their graduate student experience. "I focused on that [the GA position] instead of understanding that my tools for success were going to be learned in the classroom, and then kind of absorbed through just trial and error" (Chad). In their efforts to be full-time graduate students with parttime GA positions, setting priorities was a challenge. They felt pressure to meet the needs of their campus communities as the sole campus LGBTQRC staff member.

Aside from the negative individual consequences of participants' inability to focus on their graduate education, participants noted their limitations with institutional-level work. Some of their hopes about the change they could achieve on campus, such as organizational, policy, and practice influences, were unattainable. As one participant noted:

I'm claiming to want to do some more institutional work into deeper level things that were just not very attainable for someone who was a first-year grad student and didn't have a ton of actual resources. I just felt like a lot of my goals that I set for myself were very unattainable, but I didn't know that until I actually had the semester to see that. (Aaron)

While participants noted their limitations in resources (Tillapaugh \& Catalano, 2019), they also reported diminished agency for the work they could accomplish. Chad noted his role was one of policy research and establishment of best practices, but he was unable to move forward with his recommendations without senior-level leadership approval. Paula was aware of the lack of collaborative and intersectional programming on campus and described negative interactions with other campus offices, including multicultural affairs. "I think some people don't believe that LGBT on this campus is a cultural thing" (Paula). She was frustrated with the outcome of trying to engage in conversations as a GA. Expectations to meet campus needs came without the resources, support, time, and power to implement the changes they saw would improve LGBTQ+ campus climate.

\section{Institutional Focus on External Perceptions}

Participants noted how the existence of an LGBTQRC was window-dressing, which inhibited the impact of their work. The GAs critiqued their limited institutional support 
combined with pressure for their work to be visible and active. "I think by having a full-time staff member in the center [it] shows that you feel like it's a valid resource and it's doing things" (Paula). Participants noted that the existence of an LGBTQRC with a GA running it seemed like an empty gesture toward LGBTQ+ work on campus:

It's kind of like the "Oh, bless your heart. Oh, I am so glad we have the LGBT center." Yeah, you know why? Because it looks good. I don't have a lot of the resources I need ... - and this center has a 20 hour a week grad as opposed to full time directors and their own office space. (Nick)

For Chad, an LGBTQRC staffed by a GA was deeply problematic. "The fact that we're having a GA as the sole point of contact for LGBT student services is, for lack of a better word, kind of a joke" (Chad). The participants questioned the institutional commitment to a department when that institution did not provide any full-time staff. Given that, at best, turnover is every two years, concerns arose about the continuity of the work and the ability to foster support for students and institutional change.

Institutional power was another source for critiques. In the estimation of participants, graduate students lack agency within the institutional hierarchy in the way a full-time director might not. Aaron shared his inability to change the gender options on a scholarship application to reflect students' identities better:

I think that if there were more people with a little bit more status who were saying those things [that gender markers needed to be more inclusive on the application], that would have made a bigger impact than just a 20 hour a week GA. I don't even know what came of those conversations. (Aaron)

He felt unable to facilitate change due to his limited number of hours and the competing priorities of the role itself. Further, no one communicated the decision about the scholarship application, leaving Aaron uncertain whether that was due to his status as a GA or some other factor.

Paula characterized the lack of institutional support as financial and conceptual absences, subverting the scope of impact an established LGBTQRC might achieve. Budgets were slim, and participants rarely were trained on how to utilize what few funds were available. Seth received no budget training and relied on the LGBTQ+ student organization as his primary funding source:

So I think it was sort of weird like [LGBTQ+ student organization] has money but I don't sort of [understand the] situation. And that's because of the institutional powers that be. My supervisor at the time would be like, "Well, I've got 50 bucks here and there if you want to do this program," under some secret fund that I didn't need to know about. (Seth)

Seth described a budget dynamic that might be well-intentioned but was substantially problematic as a long-term strategy for a professional LGBTQRC staff member.

Participants believed there was an expectation to make their work visible but did not feel supported by mid-level or senior leaders. Often participants were the sole person on campus lobbying for the purpose and necessity of their LGBTQRC. "More administrators need to sit down and be a part of ... these conversations that I have every day and understand on that level why it's [the center] is so important for students like this" (Paula). Continuous advocacy work, draining for full-time professionals, was overwhelming for GAs serving in these roles. Aaron noted perceived support from campus life professionals, but he never "felt tremendous support" from university leaders to make LGBTQ+ issues important or engage in ways to fix issues. 


\section{Discussion}

There was still an assumption held by campus administrators that being a sexual minority gave individuals the necessary content knowledge to adequately fulfill the job of working in a LGBTQRC. This assumption is rather dangerous, and it is clear from the participants' conversations that this assumption is untrue. From our findings, there are significant and urgent topics for student affairs administrators to consider in terms of their professional practice.

\section{Implications of the Five Faces of Oppression on Practice}

In the case of the graduate students working as sole staff of institutional LGBTQRCs, exploitation refers to how their labor exceeds their contracted 20 hours per week to achieve their responsibilities or expectations of their labor to be equal to that of full-time professionals. The institution benefits "through a steady process of the transfer of the results of the labor of one social group to the benefit of another" (Young, 1990, p. 49). Given our participants' concerns about negotiating roles and identities, GAs may receive inadequate support from their immediate supervisors around these matters. Statistics indicated that $50-60 \%$ of student affairs professionals depart the field within their first five years of work (Tull, 2006); current structures of GAs in our study do little to counter this level of burnout and attrition. The lack of supervision and care provided to these GAs is dismal and distressing. We find alarming the dynamics that ask emerging professionals to handle immense duties and responsibilities of running their campus's LGBTQRC without mentorship, supervision, or adequate training. This is not a critique of participants' capabilities. As they said themselves, the resources necessary to be successful in their roles were absent, and participants often felt "set up to fail."

Marginalization for these graduate students is about both their work and their place within the institution as being on the periphery of campus. Marginalization is about the "depravation of cultural, practical, and institutionalized conditions for exercising capacities in a context of recognition and interaction" (Young, 1990, p. 55). The importance of LGBTQ+ students is marginal at best, as demonstrated by using GAs instead of full-time staff to direct these centers; the institutional choice to persist in utilizing GAs for complex professional roles with significant campus responsibilities reflects an institutional prioritization away from LGBTQ+ students. Institutionalized conditions reveal marginalization from the lack of endowed authority for GAs and deems the centers they serve as marginal. Here the connection to powerlessness is clear: "the powerless lack authority, status, and sense of self that professionals tend to have" (Young, 1990, p. 57).

It is understandable that the participants in this study showed clear signals of experiencing high levels of stress through their jobs. The influence of how the social identities of these GAs in their roles go unnoticed while institutions benefit from the emotional, interpersonal, and programmatic forms of labor that help influence campus environments for LGBTQ+ students. The institutionalized heterosexism and trans* oppression reflects the need of these LGBTQRCs. "Cultural imperialism involves the universalization of a dominant group's experience and culture, and its establishment as the norm" (Young, 1990, p. 59). Our participants' efforts required them to work within the norms of sexuality and gender, while they were expected to change campus climate and support students experiencing oppression. The microaggressions and resistance to the main thrust of their work for changing the campus connect with Young's (1990) notion of violence, specifically how violence is not just physical but about "the social context surrounding them, which makes them possible and even acceptable" (p. 61). Our participants felt responsible to push against institutional norms and politics in efforts to point out the possibilities that make violence against students a threat to campus safety. Often isolated, both due to their GA identity as well as their multiple social 
identities, their position required them to take responsibility for leading a LGBTQRC, putting themselves in a harsh spotlight by students, other campus administrators, and even off-campus entities. Having to then negotiate the complexity of these different dynamics was often challenging, especially without appropriate supervision. While the participants felt affirmed by many in their campus community, they still had to negotiate the visibility of their role-being the head of the LGBTQRC as graduate students-without the necessary political authority or institutional support to do the job adequately. This would be cause for concern for anyone, let alone individuals in HESA programs trying to learn how to be a competent professional.

The institutional dynamic caused participants to question the deeper purpose of LGBTQRCs. What participants described aligns with Ahmed's (2012) concept of a "tick box" approach to diversity; this is defined as "when institutions can 'show' that they are following procedures but are not really 'behind' them (showing can be a way of not committing)" (pp. 113-114). To meet the needs or expectations of institutional inclusion and fostering of LGBTQ + support, higher education leaders created LGBTQRCs. Limiting the resources to these LGBTQRCs (financial, shortterm graduate students as primary staffing, among other resources) is a shallow approach to doing LGBTQRC work on campus. Establishing an LGBTQRC on campus offers a solution without ever addressing any substantial LGBTQ+ problems on campus because the existence of the LGBTQRC obfuscates any view of the actual issues (Ahmed, 2012).

\section{Implications for Future Research}

There is a need for increased and critical research on LGBTQRCs and its staff members. Outdated is the scholarship on LGBTQ+ staff working in student affairs (Pryor et al., 2017). Existing publications do not adequately address the role of GAs serving as the sole LGBTQ+ student services staff on campus. Given the sociopolitical climate for LGBTQ+ individuals in the United States, LGBTQRCs will continue to be necessary spaces on our campuses. The landscape of higher education quickly shifts, so a limitation to our research is the age of our data. There is an inherent need for more contemporary research that discusses the experiences of those who work at such centers and insights on the organizational practices of LGBTQRCs. Further, this research would be advantageous for HESA curriculums to increase content and practice knowledge. New professionals reflected that experiences in sites of practice (e.g., assistantships) during their HESA program were "essential components" (Renn \& Jessup-Anger, 2008, p. 329). Contemporary research will bolster how HESA curriculum can engage in theory to practice pedagogy.

Lastly, we believe that future research must investigate the role of multiple identities of staff in cultural centers. Given the increasing understanding of intersectionality and how cultural centers on college and university campuses are singular identity focused (e.g., LGBTQRCs, Black Cultural Centers), there is a need to explore how staff members' multiple social identities help and/or hinder their work and professional practice within these centers. As this study demonstrated, there are varying levels in which one's social and personal identities play a role in how they believe others perceive them and how they feel about their work. Yet, one of the limitations of our study was that most of our participants identified as White, cisgender, and gay or queer. It would be important to have a more diverse understanding of how other individuals, particularly historically underrepresented racial populations and those who identify as transgender or gender non-binary, make meaning of their identities as it relates to the roles they have within LGBTQRCs. 


\section{References}

Abes, E. S. (2009). Theoretical borderlands: Using multiple theoretical perspectives to challenge inequitable power structures in student development theory. Journal of College Student Development, 50(2), 141-156. doi:10.1353/csd.0.0059

Abes, E. S. (2016). Situating paradigms in student development theory. New Directions for Student Services, 154, 9-16.

Ahmed, S. (2012). On being included: Racism and diversity in institutional life. Durham, NC: Duke University Press.

Catalano, D. C., \& Griffin, P. (2016). Sexism, heterosexism, and trans* oppression curriculum design. In M. Adams, L. A. Bell, D. Goodman, \& K. Joshi (Eds.), Teaching for diversity and social justice (3rd ed., pp. 183-211). New York, NY: Routledge.

Consortium of Higher Education LGBT Resource Professionals. (2017). Find an LGBTQ center. [Website]. Retrieved from http://www.Igbtcampus.org/find-an-lgbtq-campus-center

Cuyjet, M. J., Howard-Hamilton, M. F., Cooper, D. L., \& Linder, C. (2016). Multiculturalism on campus: Theory, models, and practices for understanding diversity and creating inclusion. Sterling, VA: Stylus.

DeJong, K., \& Love, B. J. (2015). Youth oppression as a technology of colonialism: Conceptual frameworks and possibilities for social justice education praxis. Equity \& Excellence in Education, 48(3), 489-508. doi:10.1080/ 10665684.2015 .1057086

Evans, N. J., \& Rankin, S. (1998). Heterosexism and campus violence: Assessment and intervention strategies. In A. M. Hoffman, J. H. Schuh, \& R. H. Fenske (Eds.), Violence on campus: Defining the problems, strategies for action (pp. 169-186). Gaithersburg, MD: Aspen Publishers.

Fine, L. (2012). The context of creating space: Assessing the likelihood of college LGBT center presence. Journal of College Student Development, 53(2), 285-299. doi:10.1353/csd.2012.0017

Jenkins, T. S., \& Walton, C. L. (2008). Student affairs and cultural practice: A framework for implementing culture outside the classroom. In S. R. Harper (Ed.), Creating inclusive campus environments: For cross-cultural learning and student engagement (pp. 87-101). Washington, DC: NASPA.

Kincheloe, J. L. (2001). Describing bricolage: Conceptualizing a new rigor in qualitative research. Qualitative Inquiry, 7(6), 679-692. doi:10.1177/107780040100700601

Kortegast, C. A., \& van der Toorn, M. (2018). Other duties not assigned: Experiences of lesbian and gay student affairs professionals at small colleges and universities. Journal of Diversity in Higher Education, 11(3), 268-278. doi:10.1037/ dhe0000046

Kuk, L., \& Cuyjet, M. J. (2009). Graduate preparation programs: The first step on socialization. In A. Tull, J. B. Hirt, \& S. A. Saunders (Eds.), Becoming socialized in student affairs administration: A guide for new professionals and their supervisors (pp. 89-108). Sterling, VA: Stylus.

Marine, S. B. (2011). Stonewall's legacy: Bisexual, gay, lesbian, and transgender students in higher education [ASHE Higher Education Report, 37 (4)]. San Francisco, CA: Jossey-Bass.

Marine, S. B., McLoughlin, P. J., II, \& McCarthy, T. P. (2015). Queering Harvard Yard: Four decades of progress for BGLTQ equity. In J. C. Hawley (Ed.), Expanding the circle: Creating an inclusive environment in higher education for LGBTQ students and studies (pp. 163-184). Albany: SUNY Press.

Marine, S. B., \& Nicolazzo, Z. (2014). Names that matter: Exploring the tensions of campus LGBTQ centers and trans inclusion. Journal of Diversity in Higher Education, 7, 265-281. doi:10.1037/a0037990

Michell, D., Szorenyi, A., Falkner, K., \& Szabo, C. (2017). Broadening participation not border protection: How universities can support women in computer science. Journal of Higher Education Policy and Management, 39(4), 406-422. doi:10.1080/1360080X.2017.1330821

Patton, L. (2011). Culture centers in higher education: Perspectives on identity, theory, and practice. Sterling, VA: Stylus.

Patton, M. Q. (2002). Qualitative research and evaluation methods (3rd ed.). Thousand Oaks, CA: SAGE.

Pitcher, E. N., Camacho, T. P., Renn, K. A., \& Woodford, M. R. (2016). Affirming policies, programs, and supportive services: Using an organizational perspective to understand LGBTQ+ college student success. Journal of Diversity in Higher Education, 11(2), 117-132. doi:10.1037/dhe0000048

Pryor, J. T., Garvey, J. C., \& Johnson, S. (2017). Pride and progress? 30 years of ACPA and NASPA LGBTQ presentations. Journal of Student Affairs Research and Practice, 54(2), 123-136. doi:10.1080/19496591.2016.1206020

Renn, K. A. (2010). LGBT and queer research in higher education: The state and status of the field. Educational Researcher, 39(2), 132-141. doi:10.3102/0013189X10362579

Renn, K. A., \& Jessup-Anger, E. R. (2008). Preparing new professionals: Lessons for graduate preparation programs from the national study of new professionals in student affairs. Journal of College Student Development, 49(4), 319-355. doi:10.1353/csd.0.0022

Sanlo, R., Rankin, S., \& Schoenberg, R. (2002). Our place on campus: Lesbian, gay, bisexual, transgender services and programs in higher education. Westport, CT: Greenwood Press.

Sanlo, R. L. (1998). Working with lesbian, gay, bisexual, and transgender college students: $A$ handbook for faculty and administrators. Westport, CT: Greenwood Press.

Sanlo, R. L. (2000). The LGBT campus resource center director: The new professional in student affairs. NASPA Journal, 37 (3), 485-495. doi:10.2202/0027-6014.1113

Stewart, D. L. (2011). Multicultural student services on campus: Building bridges, re-visioning community. Sterling, VA: Stylus.

Tillapaugh, D., \& Catalano, D. C. J. (2019). Structural challenges affecting the experiences of public university LGBT services graduate assistants. Journal of Diversity in Higher Education, 12(2), 126-135. doi:10.1037/dhe0000079

Tillapaugh, D., \& Nicolazzo, Z. (2015). "It's kind of apples and oranges": Gay college males' conceptions of gender transgression as poverty. Journal of Critical Scholarship on Higher Education and Student Affairs, 1(1), 67-81. 
Tull, A. (2006). Synergistic supervision, job satisfaction, and intention to turnover of new professionals in student affairs. Journal of College Student Development, 47(4), 465-480. doi:10.1353/csd.2006.0053

Yin, R. K. (2003). Case study research: Design and methods. Thousand Oaks, CA: SAGE.

Young, I. M. (1990). Justice and the politics of difference. Princeton, NJ: Princeton University Press. 